S Research Square

\title{
Radiographer-led Discharge for Emergency Care Patients, Requiring Projection Radiography of Minor Musculoskeletal Injuries: a Scoping Review
}

Jenny Shepherd ( $\sim$ jenny.shepherd@exeter.ac.uk)

University of Exeter

Ilianna Lourida

NIHR Applied Research Collaboration (ARC) South West Peninsula (PenARC), University of Exeter Medical School, University of Exeter

Robert M. Meertens

University of Exeter

\section{Research Article}

Keywords: Radiographer-led discharge, Service improvement, Early discharge, Emergency department

Posted Date: May 19th, 2021

DOI: https://doi.org/10.21203/rs.3.rs-495358/v1

License: (c) (1) This work is licensed under a Creative Commons Attribution 4.0 International License. Read Full License 


\section{Abstract}

\section{Background}

Pressure on emergency departments (ED) from increased attendance for minor injuries has been recognised in the United Kingdom. Radiographer-led discharge (RLD) has potential for improving efficiency, through radiographers trained to discharge patients or refer them for treatment at the point of image assessment. This review aims to scope all RLD literature and identify research assessing the merits of RLD and requirements to enable implementation.

\section{Methods}

We conducted a scoping review of studies relating to RLD of emergency care patients requiring projection radiography of minor musculoskeletal injuries. MEDLINE, Embase and CINAHL, relevant radiography journals and grey literature were searched. Articles were reviewed and the full texts of selected studies were screened against eligibility criteria. The data were extracted, collated and a narrative synthesis completed.

\section{Results}

Nine studies with varying study designs were included in the review. The small number of studies was possibly due to a generally low research uptake in radiography. The main outcome for five studies was reduced length of stay in ED, with recall and re-attendance to ED a primary outcome in one study and secondary outcome for three other studies. The potential for increased capacity for ED staff was recognised. Radiographers identified a concern regarding the risk of litigation and incentive of increased salary when considering RLD. The studies were broadly radiographer focussed, despite RLD spanning ED and Radiology.

\section{Conclusion}

There were a low number of RLD active radiographers, likely to be motivated individuals. However, RLD has potential for generalisability with protocol variations evident, all producing similar positive outcomes. Understanding radiography and ED culture could clarify facilitators for RLD to be utilised more sustainably into the future. Cost effectiveness studies, action research within ED, and cluster randomised controlled trial with process evaluation are needed to fully understand the potential for RLD.

The cost effectiveness of RLD may provide financial support for training radiographers and increasing their salary, with potential future benefit of reduction in workload within ED. RLD implementation would require an inter-professional approach achieved by understanding ED staff and patient perspectives and ensuring these views are central to RLD implementation.

\section{Background}

During April 2017 to March 2018 in the UK, there were 23.8 million attendances in the emergency department (ED), a $22 \%$ increase since 2008-09. Of these, $12 \%$ waited over the target four hours to be discharged or admitted, more than double the expected $5 \%{ }^{1}$. In addition, there was a $33 \%$ increase of patients attending either minor injuries units (MIU) or walk-in centres during the same time period ${ }^{1}$. To address this increase, it is appropriate to consider radiographer-led discharge (RLD) for patients with minor injuries ${ }^{2}$. RLD utilises reporting radiographers trained to either discharge patients with normal images or refer for treatment pathways ${ }^{3}$ (Table 1). This innovative pathway was recognised for its potential to reduce the pressure on ED and $\mathrm{MIU}^{2}$ and first piloted by Snaith in $2007^{3}$. Despite being successfully trialled 13 years ago $^{3}$, it is still not common practice across the $\mathrm{NHS}^{2}$. 
Table 1

Glossary of terms

\section{Radiographer Radiographer provides written comment on an $\mathrm{x}$-ray, which can be used as a guide, based on their commenting professional opinion ${ }^{9}$}

Hot reporting The radiology report being available at the time the patient leaves the department ${ }^{3}$

Image

interpretation

Skill of interpreting x-ray image developed at undergraduate level. Can extend with additional post graduate training to include giving a definitive report on findings ${ }^{8}$

Reporting radiographer

Radiographer trained at masters level to provide final clinical written reports on $x$-ray images ${ }^{3}$

Radiographer-

led discharge

Radiographers already trained to report or interpret images undertaking additional discharge

(RLD)

training, either in-house or via emergency nurse practitioner (ENP) course. RLD radiographers give diagnosis and soft tissue injury management information to patients with normal x-rays and discharge them. Patient with abnormal x-rays are referred to the appropriate treatment pathway ${ }^{2}$

The NHS plan ${ }^{4}$ in 2000 offered the opportunity of role extension for allied health professions (AHPs). Radiographers developed image reporting skills, to the accuracy levels of radiologists ${ }^{5}$, leading to improved quality through clinical error reduction ${ }^{6}$. This gave potential for improved efficiency and cost effectiveness; values identified in NHS core principles ${ }^{4}$. Since 2013 image interpretation has been included in undergraduate radiography programmes ${ }^{7}$. This training, extended at post graduate level to advanced practice through Master's degree programmes, allowed radiographers to report clinically ${ }^{8}$. Nationally in $2017,78 \%$ of hospitals utilised reporting radiographers ${ }^{8}$. RLD also required extension of radiographer training specifically for the discharge process ${ }^{3}$.

The Snaith RLD pilot study evidenced a $61 \%$ reduction in the patients' length of stay (LOS) in ED. Patients were discharged or referred for treatment at point of image assessment, by the radiographer ${ }^{3}$. Hot reporting (Table 1) was also introduced into ED, during the study period, reducing patient recalls by $52 \%$. The $1.75 \%$ patient re-attendance rate also compared favourably to re-attendance rates following discharge by junior doctors (13.1\%) and nurse practitioners (8.6\%) from other similar studies ${ }^{3}$. However, the pilot also noted there were a further $564(32 \%)$ patients hot reported as normal that RLD was not utilised for, as no management plan was provided at initial assessment ${ }^{3}$. Therefore, with a more robust process there is scope for twofold service improvements with RLD, in line with clinical streaming principles ${ }^{10}$. This is via integrated care benefits and adding value to the patient experience by shortening their journey through ED.

There is potential for improved cost effectiveness in emergency care, with image interpretation errors the leading cause of litigation in $\mathrm{ED}^{2}$. For example, use of hot reporting reduced missed fracture litigation claim costs by $66 \%$ in one NHS Trust $^{2}$. There could be further cost savings through service streamlining with radiographers discharging patients, increasing ED staff capacity for seeing other patients ${ }^{2}$.

A literature review of RLD in 2015 focussed on the impact of RLD on quality of ED services and potential barriers to RLD implementation ${ }^{11}$, but did not consider cost effectiveness. Also, the search strategy adopted by the review ${ }^{11}$ was not comprehensive. Therefore it was appropriate to complete a review with additional electronic databases, including grey literature ${ }^{12}$. More recent studies were also available which included ED staff perspectives on RLD, an area for future research identified by the 2015 review $^{11,13}$. 
RLD has been recognised as an innovative process ${ }^{2}$ and its' potential demonstrated ${ }^{3}$. Combining the aforementioned studies with recent evidence would allow synthesis of what is currently known about RLD ${ }^{12}$. Thus we conducted a scoping review aimed to summarise the evidence base of RLD for patients with minor injuries, in emergency care. This should elicit gaps in RLD research and allow identification of additional research required to fully understand the topic and aid its implementation nationally ${ }^{12}$.

\section{Methods}

The framework described by Arksey and $0^{\prime}$ Malley ${ }^{12}$ was an appropriate tool for this scoping review and formed the basis of the review protocol ${ }^{14}$. Initially, the research question and relevant studies were identified, with the included study selection made using predefined eligibility criteria. Finally, the data from the studies were extracted, charted and summarised $^{12}$.

\section{Identifying the research question}

The research question was required to be broader than expected for a systematic review but sufficiently focussed to identify all relevant literature ${ }^{12,14}$. A primary question was set, based on the Joanna Briggs Institute mnemonic for scoping reviews of population, concept and context ${ }^{15}$. The specific elements included were the population of radiographers and concept of RLD for patients with minor musculoskeletal injuries (MSK). The context was urgent or emergency care. Key inclusion and exclusion criteria were also developed (Table 2).

The international prospective register of systematic reviews (PROSPERO) was searched for a protocol based on this topic, once the question was framed ${ }^{16}$. In addition, Pubmed, Medline and Google scholar were also searched for existing systematic and scoping reviews on RLD. No protocols or existing reviews were found.

\section{Eligibility criteria}

All study designs were considered to add context and depth to the findings, in keeping with a scoping review ${ }^{12,14}$. As potential barriers for RLD may be linked to implementation and resistance to change ${ }^{17}$, rather than feasibility, it was deemed appropriate to include qualitative studies.

The study population was based on the eligibility criteria (Table 2). Therefore, radiographers with advanced training in projection radiography reporting or image interpretation for the appendicular skeleton were included. The concept for inclusion specifically pertained to RLD for minor MSK injuries of the extremities and the context was discharge or treatment referral from emergency or urgent care. As radiographer role extension was specifically identified in the NHS plan in $2000^{4}$, only UK NHS studies, post 2000, written in English, were included. 
Table 2

Inclusion and exclusion criteria

Inclusion Exclusion

\section{Population}

Radiographers

Advance practitioners

Concept

Radiographer-led discharge for projection radiography
AHP professionals other than radiographers

Any advanced practitioner who is not a radiographer
Discharge by any other professionals

Alternative types of discharge i.e. from the body

Other modalities than projection radiography

\section{Context}

Emergency department

GP or outpatient setting. Other healthcare sources which are not acute

Accident and emergency

Emergency medicine

\section{Additional eligibility requirements}

Articles published post 2000

Articles published pre 2000

Studies within the UK NHS

Private healthcare

Patients with minor injuries

Patients with major trauma

Imaging of appendicular skeleton only

\section{Identifying relevant studies}

On the 26th April $2019 \mathrm{CINAHL}$, Embase and MEDLINE databases were searched. The key words identified in Table 3 and relevant Medical Subject Headings (MESH) terms were combined using Boolean terms. The Radiography journal was hand searched by screening article titles in content pages, for articles pre-dating the March 2017 inclusion on Medline, back to January 2000.

Table 3

Summary of key words for population, concept and context

\begin{tabular}{|lll|}
\hline radiograph* $^{*}$ & discharge* $^{*}$ & emergency department \\
\hline radiology & patient discharge & accident and emergency \\
\hline radiographer-led & casualty \\
\hline & emergency medical services \\
\hline \multirow{2}{*}{ - truncation } & emergency service \\
\hline
\end{tabular}


Grey literature not available through the traditional databases were also searched ${ }^{12,14,18,19}$. This included sources identified by Public Health England ${ }^{20}$, Imaging and Therapy in Practice magazine and the University of Exeter repository (ORE). Keywords used for searching were 'radiographer-led discharge' and 'discharge by radiographer'.

A further search of the included articles reference lists and forward citation chasing was conducted ${ }^{12,21}$. Scopus medical database and Google Scholar were used for the forward citation chasing ${ }^{22}$. With a limited time scale for the review, a time deadline of the Scopus and Google Scholar searching of 9th June 2019 was set, after which no more new studies were included ${ }^{12}$.

\section{Study selection}

Once the search was completed, the citations were uploaded to Endnote software v.X8 (Thomson Reuters, New York, NY, USA $)^{12}$ and duplicates removed. A random sample of titles and abstracts were cross referenced by two reviewers ${ }^{12}$, to assess inter-assessor reliability. This was a binary check that eligibility criteria had been correctly interpreted, using a percentage agreement check of $10 \%$ of the total studies returned from searches.

Once included articles were agreed, full texts were obtained. Initially, three randomly selected articles were independently reviewed by two reviewers, using the full text screening form, based on the inclusion criteria. The reviewers then met to confirm appropriateness of the form ${ }^{12,14}$. The remaining full text articles were independently screened against the full text form by both reviewers, who were blinded to each other's results ${ }^{14}$.

\section{Charting and collating the data}

The data were extracted using a descriptive-analytical approach, and charted under the headings identified by Arksey and $0^{\prime}$ Malley ${ }^{12}$. The study characteristics were tabulated by aims, design, location, population and intervention, specifically RLD protocol method used. This process allowed emerging themes to be identified ${ }^{12}$. An overview of the characteristics was reported with further synthesis of qualitative and quantitative outcomes included. This thematic charting process identified gaps in the research evidence base, which were reported in the narrative synthesis.

Consistent with scoping review methods, study quality was not assessed ${ }^{12}$.

\section{Results}

4148 studies were identified, reducing to 11 following title and abstract screening. Full text screening left nine studies. RLD was not the main context for two articles (Fig. 1). The two reviewers discussed four articles, potentially duplicate reporting on two studies. It was agreed to include all articles, as the reports differed in context.

Three articles were sourced from electronic databases ${ }^{3,23,24}$. Hand searching identified three articles ${ }^{9,11,25}$. One study was located in the ORE ${ }^{26}$. A storyboard was identified through the PHE search ${ }^{27}$. The author was contacted to request related published articles, but no response was received. One article was provided by the author, an expert in the field, following consultation about RLD at the study outset ${ }^{13}$.

\section{Study Characteristics}

The scoping review process identified a range of study types despite limited study numbers ${ }^{12,14}$. The studies included an audit ${ }^{23}$, two pilot studies ${ }^{3,27}$ a discrete event simulation (DES) modelling study ${ }^{26}$, a feasibility study ${ }^{9}$, a survey ${ }^{24}$, a mixed methods study ${ }^{13}$ and a literature review ${ }^{11}$. The conference article did not state study type ${ }^{25}$ and potentially shared study data with the feasibility study ${ }^{9}$. The modelling and mixed methods articles were possibly based on one 
study ${ }^{13,26}$. The mixed methods study was a Health Education England report extending beyond modelling to include interviews, a focus group and training needs analysis (TNA $)^{13}$.

There was a geographical spread with two articles based in south west England ${ }^{13,26}$ and two in north east (NE) Scotland ${ }^{9,25}$. Two studies were based in north east England ${ }^{23,24}$, one in Wales ${ }^{27}$ and one in mid-Yorkshire ${ }^{3}$. The review $^{11}$ included the NE England ${ }^{23,24}$ and mid-Yorkshire studies ${ }^{3}$. Studies were mostly conducted in general hospital EDs, with the Scottish articles based in community hospital MIUs ${ }^{9,25}$ (Table 4).

Patient numbers in RLD study arms, where stated, ranged from five 27 to $497^{23}$, with modelling extending to $1303^{26}$. The questionnaire uptake was 101 respondents from around 500 contacted $^{24}$. Excluding modelling studies ${ }^{13,26}, 3$ was the maximum number of RLD radiographers per study ${ }^{3}$. Howard identified RLD radiographers driving the process; a relevant concept if radiographer motivation is pertinent to RLD success ${ }^{9}$.

Different patient age ranges were included, where stated, with adults included in three studies ${ }^{3,9,23}$ and paediatrics only in one ${ }^{27}$. Two studies excluded patients under five years old ${ }^{3,23}$ and one study excluded under two year olds ${ }^{9}$, whilst Jenkins only included paediatrics ${ }^{27}$ Justifications for paediatric exclusion were difficulty in clinical assessment ${ }^{3}$ and potentially more complex symptoms ${ }^{23}$.

The primary aim for five studies was reviewing impact of RLD on length of stay (LOS) in the emergency setting, either arrival to discharge $e^{3,25,26}$ or $x$-ray to discharge ${ }^{23,27}$. The other studies assessed RLD feasibility ${ }^{9}$, RLD impact on ED services \& professional practice ${ }^{11}$, and radiographer attitudes to RLD $^{24}$. Knapp et al primarily scoped local reporting radiographer training requirements ${ }^{13}$.

Secondary aims varied from impact on ED recall and re-attendance rates ${ }^{23,25}$ to identifying potential barriers for RLD ${ }^{11}$ and reviewing use of a DES model as a support tool for using RLD 26 (Table 4).

\section{RLD methodology}

RLD protocol differed across the studies. The main theme was radiographers discharging patients with normal $x$-rays, although giving basic treatment advice was also stated in five studies $3,9,11,23,26$. Three studies required a discharge plan written at initial clinical assessment to be used by the discharging radiographer ${ }^{3,9,23}$. Four studies specified extremity only examinations ${ }^{3,9,23,26}$, with this detail not stated for the remaining studies. Two studies modelled RLD pathways with differing variations, based on process mapping within $\mathrm{ED}^{13,26}$. An insightful RLD perspective was also provided by a patient focus group ${ }^{13}$. The literature review ${ }^{11}$ and survey ${ }^{24}$ did not have a standard interpretation for RLD but included any variations. The focus of these studies was more in terms of an overview of the RLD concept and consideration of radiographer opinion (Table 4). 
Table 4

Study characteristics

\begin{tabular}{|c|c|c|c|c|c|c|}
\hline Authors & $\begin{array}{l}\text { Primary aim } \\
\text { of the study }\end{array}$ & $\begin{array}{l}\text { Secondary } \\
\text { aim of the } \\
\text { study }\end{array}$ & $\begin{array}{l}\text { Study type } \\
\text { and design }\end{array}$ & $\begin{array}{l}\text { Location } \\
\text { and site } \\
\text { numbers }\end{array}$ & $\begin{array}{l}\text { Study } \\
\text { population and } \\
\text { participant } \\
\text { numbers }\end{array}$ & $\begin{array}{l}\text { Intervention } \\
\text { duration, type } \\
\text { and comparator }\end{array}$ \\
\hline $\begin{array}{l}\text { Barter } \\
2015^{11}\end{array}$ & $\begin{array}{l}\text { RLD impact } \\
\text { on quality of } \\
\text { ED services } \\
\text { and } \\
\text { professional } \\
\text { practice }\end{array}$ & $\begin{array}{l}\text { Examine } \\
\text { barriers and } \\
\text { disadvantages } \\
\text { of RLD }\end{array}$ & $\begin{array}{l}\text { Review of } \\
\text { literature } \\
\text { for RLD }\end{array}$ & $\begin{array}{l}\text { Not clearly } \\
\text { stated } \\
\text { (NCS) }\end{array}$ & $\begin{array}{l}\text { Patients } \\
\text { receiving RLD } \\
\text { compared with } \\
\text { standard } \\
\text { discharge, } \\
\text { radiographers } \\
\text { and } \\
\text { radiologists. } \\
\text { Participant } \\
\text { numbers NCS }\end{array}$ & $\begin{array}{l}\text { All studies of } \\
\text { RLD from } 2000 \\
\text { until } \\
\text { publication, } \\
\text { including all } \\
\text { interpretations } \\
\text { of RLD }\end{array}$ \\
\hline $\begin{array}{l}\text { Henderson } \\
\text { et al } \\
2012^{23}\end{array}$ & $\begin{array}{l}\text { Can RLD } \\
\text { reduce x-ray } \\
\text { to discharge } \\
\text { LOS }^{\text {b }} \text { without } \\
\text { impact on } \\
\text { patient } \\
\text { outcome }\end{array}$ & $\begin{array}{l}\text { NCS but } \\
\text { arrival to } \\
\text { discharge LOS } \\
\text { was compared } \\
\text { in the study. } \\
\text { Recall and re- } \\
\text { attendance } \\
\text { rates }\end{array}$ & $\begin{array}{l}\text { Prospective } \\
\text { audit of } \\
\text { RLD }\end{array}$ & $\begin{array}{l}1 \text { North } \\
\text { east (NE) } \\
\text { England } \\
\text { General } \\
\text { Hospital } \\
\text { ED } \\
\text { department }\end{array}$ & $\begin{array}{l}>5 \text { years old. } \\
\text { Below elbow/ } \\
\text { knee injury, able } \\
\text { to weight bear } \\
\text { and be } \\
\text { discharged after } \\
\text { x ray with no } \\
\text { follow up. } 497 \\
\text { in intervention, } \\
2632 \\
\text { comparators }\end{array}$ & $\begin{array}{l}3 \text { month pilot } \\
\text { audit then } 2 \\
\text { year audit. RLD } \\
\text { defined as } \\
\text { reporting } \\
\text { radiographer } \\
\text { discharging } \\
\text { patients, with } \\
\text { advice, whose } \\
\text { ENPC or Doctor } \\
\text { wrote a } \\
\text { discharge plan } \\
\text { for negative } x \\
\text { ray findings at } \\
\text { initial } \\
\text { consultation. } \\
\text { Standard } \\
\text { discharge } \\
\text { comparator }\end{array}$ \\
\hline $\begin{array}{l}\text { Howard } \\
2017^{9}\end{array}$ & $\begin{array}{l}\text { Feasibility of } \\
\text { RLD in a } \\
\text { community } \\
\text { hospital }\end{array}$ & $\begin{array}{l}\text { Explore the } \\
\text { impact of RLD } \\
\text { in terms of the } \\
\text { patient } \\
\text { pathway }\end{array}$ & $\begin{array}{l}\text { Feasibility } \\
\text { comparing } \\
\text { RLD with } \\
\text { standard } \\
\text { discharge } \\
\text { comparator }\end{array}$ & $\begin{array}{l}1 \\
\text { community } \\
\text { hospital } \\
\text { Minor } \\
\text { injury unit } \\
\text { in NE } \\
\text { Scotland }\end{array}$ & $\begin{array}{l}\text { > } 2 \text { years old for } \\
\text { extremity } \\
\text { musculoskeletal } \\
\text { injury below } \\
\text { knee \& shoulder. } \\
\text { Participant } \\
\text { number not } \\
\text { clearly stated }\end{array}$ & $\begin{array}{l}6 \text { month, RLD } \\
\text { process of } \\
\text { discharge of } \\
\text { patients with } \\
\text { minor } \\
\text { musculoskeletal } \\
\text { injuries, with } \\
\text { written } \\
\text { radiographer } \\
\text { comment of no } \\
\text { acute } \\
\text { bony/joint } \\
\text { abnormality. } \\
\text { Radiographer } \\
\text { offers advice/ } \\
\text { minor } \\
\text { treatment. } \\
\text { Standard } \\
\text { discharge } \\
\text { comparator }\end{array}$ \\
\hline
\end{tabular}




\begin{tabular}{|c|c|c|c|c|c|c|}
\hline Authors & $\begin{array}{l}\text { Primary aim } \\
\text { of the study }\end{array}$ & $\begin{array}{l}\text { Secondary } \\
\text { aim of the } \\
\text { study }\end{array}$ & $\begin{array}{l}\text { Study type } \\
\text { and design }\end{array}$ & $\begin{array}{l}\text { Location } \\
\text { and site } \\
\text { numbers }\end{array}$ & $\begin{array}{l}\text { Study } \\
\text { population and } \\
\text { participant } \\
\text { numbers }\end{array}$ & $\begin{array}{l}\text { Intervention } \\
\text { duration, type } \\
\text { and comparator }\end{array}$ \\
\hline $\begin{array}{l}\text { Howard } \\
\text { and Craib } \\
2018^{25}\end{array}$ & $\begin{array}{l}\text { Assess if RLD } \\
\text { reduced } \\
\text { patient LOS }\end{array}$ & $\begin{array}{l}\text { Does RLD } \\
\text { reduce patient } \\
\text { recall or re- } \\
\text { attendance } \\
\text { rates }\end{array}$ & $\begin{array}{l}\text { Not clearly } \\
\text { stated }\end{array}$ & $\begin{array}{l}1 \\
\text { community } \\
\text { hospital } \\
\text { MIU in NE } \\
\text { Scotland }\end{array}$ & $\begin{array}{l}30 \text { patients with } \\
\text { no bony injury } \\
\text { on x-ray }\end{array}$ & $\begin{array}{l}\text { Duration not } \\
\text { clearly stated. } \\
\text { RLD process } \\
\text { defined as } \\
\text { discharge of } \\
\text { patients with no } \\
\text { bony or joint } \\
\text { injury. Standard } \\
\text { discharge } \\
\text { comparator. }\end{array}$ \\
\hline $\begin{array}{l}\text { Jenkins } \\
2015\end{array}$ & $\begin{array}{l}\text { Can RLD } \\
\text { reduce x-ray } \\
\text { to discharge } \\
\text { LOS, improve } \\
\text { patient flow } \\
\text { with RLD }\end{array}$ & $\begin{array}{l}\text { Assess if RLD } \\
\text { improves } \\
\text { overall patient } \\
\text { experience }\end{array}$ & $\begin{array}{l}\text { Pilot study } \\
\text { of RLD }\end{array}$ & $\begin{array}{l}1 \text { hospital } \\
\text { emergency } \\
\text { unit in } \\
\text { Wales }\end{array}$ & $\begin{array}{l}\text { Intervention } 5 \\
\text { children with } \\
\text { suspected } \\
\text { fractures. } \\
\text { Standard } \\
\text { discharge } \\
\text { comparator of } 6 \\
\text { children } \\
\text { attending same } \\
\text { date and time in } \\
\text { previous year }\end{array}$ & $\begin{array}{l}1 \text { afternoon of } \\
\text { reporting } \\
\text { radiographer } \\
\text { using RLD for } \\
\text { paediatrics, } \\
\text { following } \\
\text { competency } \\
\text { based } 30 \text { hour } \\
\text { prep including } \\
\text { treatment } \\
\text { advice and } \\
\text { recognising } \\
\text { when follow up } \\
\text { treatment is } \\
\text { required. } \\
\text { Standard } \\
\text { discharge } \\
\text { comparator. }\end{array}$ \\
\hline $\begin{array}{l}\text { Knapp et } \\
\text { al } 2016^{13}\end{array}$ & $\begin{array}{l}\text { Investigate } \\
\text { local } \\
\text { requirement } \\
\text { for reporting } \\
\text { radiographers }\end{array}$ & $\begin{array}{l}\text { Review the } \\
\text { potential } \\
\text { application of } \\
\text { RLD }\end{array}$ & $\begin{array}{l}\text { TNA }{ }^{\mathrm{e}}, \\
\text { focus } \\
\text { groups, } \\
\text { interviews } \\
\text { and } \\
\text { discrete } \\
\text { event } \\
\text { simulation } \\
\text { for RLD }\end{array}$ & $\begin{array}{l}\text { South west } \\
\text { England, } 2 \\
\text { site } \\
\text { Training } \\
\text { needs } \\
\text { analysis } \\
\text { and } 1 \text { site } \\
\text { modelling }\end{array}$ & $\begin{array}{l}3 \text { ED interviews. } \\
8 \text { ENPs, } 2 \text { ED } \\
\text { consultants, } 20 \\
\text { radiographers } \\
\text { training needs } \\
\text { analysis. Focus } \\
\text { group with } \\
\text { patients/carers. } \\
\text { Modelling of ED } \\
\text { data matching } \\
\text { RLD criteria- } \\
\text { number NCS }\end{array}$ & $\begin{array}{l}3 \text { interviews and } \\
1 \text { focus group } \\
\text { meeting with } \\
\text { researchers. } \\
\text { TNA for image } \\
\text { interpretation } \\
\text { and discharge, } \\
\text { numbers NCS. } \\
\text { Modelling } \\
\text { based on } \\
\text { historic data } \\
\text { from } 2 \text { years. } \\
\text { RLD was Not } \\
\text { clearly stated }\end{array}$ \\
\hline $\begin{array}{l}\text { Lumsden } \\
\& \text { Cosson } \\
2015^{24}\end{array}$ & $\begin{array}{l}\text { Radiographer } \\
\text { attitudes to } \\
\text { RLD }\end{array}$ & $\begin{array}{l}\text { Radiographer } \\
\text { opinions of } \\
\text { salary with } \\
\text { RLD }\end{array}$ & $\begin{array}{l}\text { Cross- } \\
\text { sectional } \\
\text { design } \\
\text { survey }\end{array}$ & $\begin{array}{l}7 \text { hospitals } \\
\text { across NE } \\
\text { England }\end{array}$ & $\begin{array}{l}300-500 \\
\text { questionnaires } \\
\text { sent to } \\
\text { radiographers. } \\
101 \text { participant } \\
\text { uptake }\end{array}$ & $\begin{array}{l}\text { Survey of } \\
\text { radiographer } \\
\text { views of RLD } \\
\text { with no single } \\
\text { RLD definition. } \\
\text { Timeframe not } \\
\text { clearly stated } \\
\text { for data } \\
\text { gathering. }\end{array}$ \\
\hline
\end{tabular}




\begin{tabular}{|c|c|c|c|c|c|c|}
\hline Authors & $\begin{array}{l}\text { Primary aim } \\
\text { of the study }\end{array}$ & $\begin{array}{l}\text { Secondary } \\
\text { aim of the } \\
\text { study }\end{array}$ & $\begin{array}{l}\text { Study type } \\
\text { and design }\end{array}$ & $\begin{array}{l}\text { Location } \\
\text { and site } \\
\text { numbers }\end{array}$ & $\begin{array}{l}\text { Study } \\
\text { population and } \\
\text { participant } \\
\text { numbers }\end{array}$ & $\begin{array}{l}\text { Intervention } \\
\text { duration, type } \\
\text { and comparator }\end{array}$ \\
\hline $\begin{array}{l}\text { Rachuba } \\
\text { et al } \\
2018^{26}\end{array}$ & $\begin{array}{l}\text { Use evidence } \\
\text { based model } \\
\text { to review } \\
\text { impact on } \\
\text { LOS for RLD } \\
\text { suitable } \\
\text { patients }\end{array}$ & $\begin{array}{l}\text { Can discrete } \\
\text { event } \\
\text { simulation } \\
\text { modelling be } \\
\text { used as a } \\
\text { decision } \\
\text { support tool } \\
\text { for RLD }\end{array}$ & $\begin{array}{l}\text { Discrete } \\
\text { event } \\
\text { simulation } \\
\text { of } 2 \\
\text { pathways } \\
\text { using RLD }\end{array}$ & $\begin{array}{l}1 \text { South } \\
\text { west } \\
\text { England } \\
\text { district } \\
\text { general } \\
\text { hospital }\end{array}$ & $\begin{array}{l}\text { Patients who } \\
\text { either had minor } \\
\text { appendicular } \\
\text { injuries or lower } \\
\text { limb injuries. } \\
1303 \text { in } \\
\text { intervention } \\
\text { group and } 1507 \\
\text { in comparator } \\
\text { group }\end{array}$ & $\begin{array}{l}23 \text { months } \\
\text { historic data } \\
\text { modelling } \\
\text { pathways for } \\
\text { RLD. RLD } \\
\text { defined as; } \\
\text { patient with no } \\
\text { other condition } \\
\text { and normal x } \\
\text { ray, discharged } \\
\text { with appropriate } \\
\text { instructions, } \\
\text { and doctor pre- } \\
\text { authorisation. } \\
\text { Modelling data } \\
\text { compared to } \\
\text { simulated } \\
\text { standard } \\
\text { discharge. }\end{array}$ \\
\hline $\begin{array}{l}\text { Snaith } \\
2007^{3}\end{array}$ & $\begin{array}{l}\text { Assess if RLD } \\
\text { could reduce } \\
\text { LOS in A\&Ef } \\
\text { pathway }\end{array}$ & $\begin{array}{l}\text { Could hot } \\
\text { reporting } \\
\text { reduce recall } \\
\text { rate }\end{array}$ & $\begin{array}{l}\text { Pilot study } \\
\text { of RLD }\end{array}$ & $\begin{array}{l}1 \text { Mid- } \\
\text { Yorkshire } \\
\text { hospital } \\
\text { A\&E } \\
\text { department }\end{array}$ & $\begin{array}{l}114 \text { patients } \\
\text { between } 5 \text { and } \\
65 \text { years old, } \\
\text { with } x \text { ray } \\
\text { imaging of } \\
\text { distal } \\
\text { extremities, } \\
\text { excluding knees } \\
\text { and shoulders }\end{array}$ & $\begin{array}{l}4 \text { month pilot of } \\
\text { RLD, defined as } \\
\text { radiographers } \\
\text { hot reporting } \\
\text { images and } \\
\text { discharging } \\
\text { patients with } \\
\text { advice, using } \\
\text { discharge plan } \\
\text { written at initial } \\
\text { assessment. } \\
\text { Standard } \\
\text { discharge } \\
\text { comparator }\end{array}$ \\
\hline
\end{tabular}

\section{Quantitative Outcomes}

The predominant outcome measure was time of patient arrival in ED to discharge for RLD, compared to standard discharge practice (SDC). Eight studies reported a significant LOS reduction using RLD 3,9,11,13,23,25,26,27. Two studies omitted numerical data ${ }^{9,25}$ (Table 4). Henderson et al ${ }^{23}$ reported $17 \%$ (21 min) mean RLD LOS reduction, compared with SDC, which also included RLD data (Fig. 2). No standalone SDC data was included; however, with no overlap of confidence intervals (Cls) for RLD results were still statistically significant (Table 5). Snaith ${ }^{3}$ reported RLD LOS reduction of $61 \%$ (82min) and after RLD treatment referral of $41 \%$ (63min).

Jenkins ${ }^{27}$ piloted $x$-ray to discharge LOS, with $72 \%$ reduction. Henderson ${ }^{23}$ also reviewed x-ray to discharge times for RLD, with 12.9 min (SD 9.81) mean LOS. No SDC data was cited. The review ${ }^{11}$ included results from the Henderson et $\mathrm{al}^{23}$ and Snaith ${ }^{3}$ studies (Table 5).

Varying levels of RLD were modelled, compared to simulated standard discharge (SSD). The results reported here used $50 \%$ and $100 \%$ RLD, compared to SSD. This was formerly to align with the intervention, comparator results from other 
studies and latterly a more realistic estimate of RLD uptake (Fig. 2). Both results demonstrated reduced LOS, against $\mathrm{SSD}^{13}$. Differing days of the week utilising RLD were also modelled. With $51 \%$ of RLD eligible patients presenting at the weekend, impact of RLD on these 48 hours gave a reduction in ED overall LOS of $10 \%$. The limiting factor for this was only $55 \%$ of all ED patients were imaged ${ }^{26}$. Impact on ED capacity was modelled with around 500 RLD discharges allowing time for roughly 300 additional clinical examinations by ED staff ${ }^{26}$.

Secondary outcome measures for recall and re-attendance within 28 days from original attendance showed significant reductions. Henderson et $\mathrm{al}^{23}$ identified RLD re-attendance rate was $2.62 \%$, and either not clinically significant or unrelated. SDC re-attendance rates were $7.06 \%$ of which $1.75 \%$ were clinically significant. The odds ratio of re-attending with the same injury through standard discharge, compared to RLD was significant at $8.36(95 \% \mathrm{Cl} 2.05 \text { to } 34.08)^{23}$. However, given the wide $\mathrm{Cls}$, the study may be underpowered and therefore this may introduce uncertainty into the results ${ }^{29}$. Snaith reported RLD re-attendance rates of $1.75 \%^{3}$, compared against other study results of $13.1 \%$ and $8.6 \%$ for junior doctors and nurse practitioners respectively ${ }^{3}$. Howard and Craib saw no patients re-attending and one patient recall, with no change in management with $\operatorname{RLD}^{25}$ (Table 5). 
Table 5

Study results

\begin{tabular}{|c|c|c|}
\hline Authors & Outcome Measures & Results \\
\hline \multirow[t]{2}{*}{$\begin{array}{l}\text { Barter } \\
2015^{11}\end{array}$} & $\begin{array}{l}\text { Primary: } L^{2} S^{a} \text { in } E D^{b} \text { with } R^{\prime} D^{c} \\
\text { Vs SDC } \text {. Comparing re- } \\
\text { attendance rates }\end{array}$ & $\begin{array}{l}\text { Reduced LOS with RLD of } 82 \text { min and }>20 \text { min. Reduced RLD re- } \\
\text { attendance } 53 \% \text { and } 26.6 \% \text { for } 2 \text { included studies }\end{array}$ \\
\hline & Secondary: Attitudes to RLD & $\begin{array}{l}\text { RLD could reduce LOS and improve services. Concerns over } \\
\text { potential for litigation }\end{array}$ \\
\hline \multirow[t]{2}{*}{$\begin{array}{l}\text { Henderson } \\
\text { et al } \\
2012^{23}\end{array}$} & $\begin{array}{l}\text { Primary: Overall LOS with RLD Vs } \\
\text { SDC }\end{array}$ & $\begin{array}{l}\text { RLD mean } 100.9 \text { min. (SD } 42.503,95 \% \mathrm{Cl} 97.2 \text { to } 104.7) \text {. SDC } \\
\text { (mean of data during audit, including RLD data) } 122 \mathrm{~min} \text { (SD } \\
48.220,95 \% \mathrm{Cl} 120.3 \text { to } 123.7 \text { ) }\end{array}$ \\
\hline & $\begin{array}{l}\text { Secondary: Clinically significant } \\
\text { (CS) false negative results, and } \\
\text { re-attendance rates within } 28 \text { day } \\
\text { period }\end{array}$ & $\begin{array}{l}\text { RLD false negative CS rate } 0 \% \text {. SDC false negative CS rate } \\
1.33 \% \text {. Odds ratio (OR) false negative ED: RLD } 10.59(95 \% \mathrm{Cl} \\
1.46 \text { to } 76.68) \text {. RLD re-attendance rate } 2.62 \% \text {, SDC } 7.06 \% \text { with } \\
1.75 \% \text { CS. OR re-attending with same injury ED:RLD } 8.36(95 \% \mathrm{Cl} \\
2.05 \text { to } 34.08)\end{array}$ \\
\hline
\end{tabular}

Howard Primary: NCS. Patient re- No patient re-attended

$2017^{9}$ attendance

Secondary: Arrival to discharge LOS rates were reduced; no numerical data included time

Howard Primary: Time from arrival to RLD reduced length of stay. Minimum journey time 26 min and Craib

$2018^{25}$ discharge with RLD

Secondary: re-attendance or $\quad$ No re-attendance, one recalled, no management change recalls

Jenkins Primary: LOS x-ray to discharge

$2015^{27} \quad$ with RLD Vs SDC

RLD mean $12.4 \mathrm{~min}, 72 \%$ LOS reduction. RLD with treatment pathway $18 \mathrm{~min}, 59 \%$ LOS reduction. SDC (mean of data from previous year) $44 \mathrm{~min}$.

Secondary: Satisfaction surveys $\quad 100 \%$ satisfaction rating from both staff and patients

Knapp et

al $2016^{13}$

Primary: TNA ${ }^{\mathrm{e}}$ for image interpretation and discharge

Secondary: DESg modelling impact on LOS with RLD. Interviews and focus group for RLD

Lumsden \& Cosson $2015^{24}$

Primary: Survey around concept of RLD and comparison of qualitative and quantitative responses

Rachuba Primary: modelled LOS in ED with et al RLD with SDC

$2018^{26}$

Snaith $2006^{3}$

Secondary: Analysis of DES modelling pathways for RLD (1) increasing RLD use (3) on different days of the week Radiographer sensitivity mean $66 \%$, specificity $78 \%$, accuracy $71 \%$. ENP ${ }^{f}$ sensitivity $67 \%$, specificity $54 \%$, accuracy $62 \%$

RLD 98.11 min $27 \%$ LOS reduction, SDC 134.07 min LOS, using $100 \%$ RLD. Interviews - more training required for RLD. Focus group - patient support for RLD

$>70 \%$ RLD would help: waiting time targets, LOS in hospital, inter-professional working. $85 \%$ stated salary as incentive for RLD. Litigation highest concern (68\%)

RLD mean 98min 66\% LOS reduction. SDC 148min when imaging requested at assessment

(1) Reduction of $>50$ mins, imaging requested at triage rather than clinical assessment. (2) LOS decreases as RLD increases. (3) Using RLD at weekends, when $51 \%$ of all RLD eligible patients present decreases overall ED LOS by average 10\%

SDC (included patients not requiring imaging) $134 \mathrm{~min}$. RLD no treatment 52 min, $61 \%$ LOS reduction. RLD with treatment average $71 \mathrm{~min}, 47 \%$ LOS reduction 


\begin{tabular}{|lll|}
\hline Authors & Outcome Measures & Results \\
\hline $\begin{array}{l}\text { Secondary: Number of patients } \\
\text { using RLD Vs SDC and patient } \\
\text { recall rates }\end{array}$ & $\begin{array}{l}114 / 1760 \text { (15.9\%) used RLD. Recall rate reduced by 52\% when } \\
\text { compared with data from the same time period in previous } \\
\text { years. }\end{array}$ \\
$\begin{array}{l}\text { a - Length of stay b - emergency department c- radiographer-led discharge } \mathrm{d} \text { - standard discharge comparator e - } \\
\text { training needs analysis f - emergency nurse practitioner } \mathrm{g} \text { - Discrete event simulation } \\
\text { Note: Standard deviations (SD) and confidence intervals (CI) not reported unless stated }\end{array}$ \\
\hline
\end{tabular}

\section{Qualitative Outcomes}

A range of qualitative methods were used $11,13,24,27$. The radiographer questionnaire used snowball sampling across hospitals with an estimated $30 \%$ response rate ${ }^{24}$. The respondents were generally positive about RLD, recognising potential benefits. The requirement for salary to reflect the additional training and responsibility was a motivational point, and litigation the main concern ${ }^{24}$.

The patient satisfaction survey was $100 \%$ positive about RLD 27 . Patients appreciated not having time wasted and A\&E staff thought RLD was a good idea and the trial worked well ${ }^{27}$. Knapp et al encompassed a patient and public involvement (PPI) focus group and ED staff interviews ${ }^{13}$. The PPI group identified positives of reducing waiting times, increased patient satisfaction and potential cost effectiveness. Concerns were possible missed diagnosis and increased risk of litigation. Radiographer competency to discharge, patient safeguarding and pathway changes was raised during ED interviews ${ }^{13}$. Appropriate training, competency use and expertise in discharge were discussed in other studies $^{23,24}$.

\section{Discussion}

In this scoping review, eight primary studies and one literature review were identified addressing RLD in either ED or MIU at various UK locations. This limited number of studies may in part be due to a low uptake of research activity in radiography in general ${ }^{30}$.

Differing RLD methodologies were described and those investigating LOS evidenced reductions with RLD, compared to $\mathrm{SDC}^{3,9,11,13,23,25,26,27}$. RLD demonstrated potential to increase clinical assessment capacity for ED staff ${ }^{3,13,27}$, and therefore staff efficiency ${ }^{11,23,26}$. This was also true for remote access general practitioners ${ }^{25}$. RLD was a variable protocol-driven process offering potential of generalisability and widespread implementation ${ }^{31}$.

Another theme was reduction in image interpretation errors improving recall and re-attendance rates ${ }^{3,23,25}$. This could improve patient outcome ${ }^{32}$ and decrease likelihood of litigation ${ }^{33}$; a key concern of radiographers surveyed ${ }^{24}$. Radiographer hot reporting has demonstrated cost effectiveness with significant reductions in interpretive errors, compared to ED clinicians ${ }^{34}$. Therefore RLD cost effectiveness was also likely, combining hot reporting with improved staffing efficiency.

The studies identified positive outcomes, albeit mostly with short time frames ${ }^{3,27}$ and small sample sizes ${ }^{29}$. It was important to understand why RLD was not more widely utilised. The concern of litigation has already been identified ${ }^{24}$. A further consideration was radiography culture, where a less supportive work environment could impede role development ${ }^{35}$. At non-RLD sites, radiographers surveyed preferred commenting on images to RLD; this was the reverse 
for RLD active sites ${ }^{24}$. This could be further explained through resistance by radiographers to change ${ }^{35}$, or less confidence with an unfamiliar process ${ }^{24}$. Also, the small number of RLD active radiographers, up to three ${ }^{3}$ per study was noted. RLD radiographers could be considered champions actively promoting the initiative ${ }^{31}$, within a supportive culture $^{35}$. They would have resistance to departmental culture issues through belief in RLD ${ }^{31}$. Generalisability of RLD ${ }^{28}$ may therefore be reliant on the presence of champions, rather than a concept accepted by all appropriately qualified radiographers ${ }^{31}$.

With low RLD radiographer numbers, inconsistent uptake of RLD could be expected ${ }^{3,23}$. Integration of RLD would require consistent use of the protocol-driven process ${ }^{31}$ requiring more RLD radiographers. This was implemented following one study which extended RLD service to evenings and weekends ${ }^{23}$. Pathways of RLD use on different days of the week were also modelled ${ }^{26}$. With $51 \%$ of RLD eligible patients attending ED at the weekend; efficient and potentially cost effective use of RLD could occur on these days ${ }^{26}$.

Further themes emerged around inter-professional working 9,13,25 and radiographer training in discharge e $^{3,13,23,24}$. Radiographers consistently interpreted images more accurately than they expected to ${ }^{7}$. Therefore, future training emphasis requires focus on discharge ${ }^{3}$. Given the radiographers' concern over litigation ${ }^{24}$, use of protocol-driven pathways and appropriate governance systems ${ }^{2}$ could encourage engagement.

ED staff could be motivated to support this competency-based training in discharge, once their increased workload capacity was recognised $3,13,27$. This capacity was through a decrease in the number of clinical assessments required with increased use of $\mathrm{RLD}^{26}$. In addition, ED clinician engagement in protocol development and implementation should reduce the potential of RLD appropriate patients presenting without a management plan ${ }^{3,31}$.

\section{Strengths and limitations}

This is the first scoping review on RLD utilising a comprehensive searching strategy. As such, there is inclusion of both quantitative outcomes and qualitative content allowing contextualisation of the current RLD evidence base.

Ideally there would have been two reviewers at abstract screening stage and reviewing data extraction stages ${ }^{14}$. However, the $10 \%$ title and abstract check and full text screening produced full agreement between assessors.

The quality of studies was not assessed ${ }^{12,14}$. Small sample sizes were identified as limitations ${ }^{3,27}$, with one study having five participants ${ }^{27}$. Larger sample sizes would have increased the power of the study and therefore likelihood of demonstrating true effect of RLD ${ }^{29}$. Henderson ${ }^{23}$ included SD and $\mathrm{Cl}$ in results, which acknowledged variance of LOS, with patients not discharged within the expected four hours ${ }^{1}$. This was omitted by other studies therefore variance of waiting times could impact study results ${ }^{29}$.

Potentially there was a further bias with the focus from the radiographer perspective, despite RLD overlapping with $\mathrm{ED}^{25}$. Knapp et al did include interviews with ED staff and PPI focus group, although extending this to ED based studies would address this ${ }^{13}$.

\section{Future research}

The narrative synthesis evidenced areas where further investigation could be considered. Reduced recall and reattendance ${ }^{3,23}$ and service streamlining were identified; however financial impact was not explored. Quality-adjusted life-year (QALY) benefits for patients are possible with increased likelihood of receiving the correct treatment at initial 
presentation $^{32}$. Hot reporting identified $£ 23.40$ saving per patient ${ }^{8}$, therefore a good rational for extending DES modelling ${ }^{26}$ to a cost effectiveness study of RLD across radiology and ED. Savings could offset the cost of training and salary increase for radiographers, a motivation for engagement with $\mathrm{RLD}^{24}$. A previous study identified radiographer reporting as more cost effective than radiologists. However, further work was required for implementation of the pathway ${ }^{36}$. Innovative thinking between radiology and ED would be required to action the cost effectiveness outcome.

The majority of studies focussed on the radiographer role and Henderson et al ${ }^{23}$ recommended a randomised controlled trial (RCT) as further research. Given the variations in RLD, a cluster RCT with process evaluation would be appropriate to aid fidelity of implementation and give context to outcome variations ${ }^{37,38}$. This process would include other stakeholders' perspectives, such as ED staff and patients ${ }^{25}$. As small sample sizes have been identified as study limitations, this would ensure use of larger sample sizes and therefore should give more power to the study ${ }^{37,38}$. Alternatively, action research - problem solving and improving practice whilst actively undertaking the discharge role, would be a relevant research method, encompassing all relevant parties ${ }^{38,39}$.

Emphasis specifically on the discharge element was required, as the innovative element of RLD ${ }^{2}$. This could be achieved through DES modelling ${ }^{26}$ of RLD, from the ED perspective, given the evidence of capacity increase ${ }^{3,13,27}$. Alternatively, a time and motion study - monitoring and timing the specific RLD activities, would identify inefficient areas or give improvement targets ${ }^{40}$ within the discharge process. This research could directly address the requirement to manage the increasing number of ED and MIU patients $3,10,25,26$.

\section{Conclusion}

A limited evidence base of nine RLD studies identified potential benefits for the patient, radiographer and ED. Journey time through ED and likelihood of recall or re-attendance could be reduced and ED staff gain increased clinical assessment capacity. A cost effectiveness study could define RLD financial impact and provide funding to train radiographers and increase their salary; an incentive for engaging with RLD. Further qualitative work to examine the impact of this interdepartmental initiative may be the final key to implementation. Understanding the culture within the radiography department and considering the perspectives of all involved by including process evaluations with future quantitative studies could give a broader picture of the RLD process. RLD success is not only reliant on radiographer uptake, but dependant on acceptance by both ED staff and patients themselves.

\section{Abbreviations}




\begin{tabular}{|ll|}
\hline ED: emergency department & RLD: radiographer-led discharge \\
\hline MIU: minor injuries unit & NHS: national health service \\
\hline ENP: emergency nurse practitioner & AHP: allied healthcare professional \\
\hline LOS: length of stay & MSK: musculoskeletal \\
\hline UK: united kingdom & ORE: Open Research Exeter \\
\hline PHE: public health England & TNA: training needs analysis \\
\hline NE: North East & DES: discrete event simulation \\
\hline SDC: standard discharge comparator & Cl: confidence interval \\
\hline SSD: simulated standard discharge & PPI: patient public involvement \\
\hline SD: standard deviation & QALY: quality adjusted life year \\
\hline RCT: randomised controlled trial & \\
\hline
\end{tabular}

\section{Declarations}

Ethics approval and consent to participate: was not applicable for this research.

Consent for publication: not applicable

Availability of data and materials: All data used and analysed during this study are included in this published article.

Competing interests: The authors declare that they have no competing interests. However, it should be noted that the authors JS and RMM are employed by the same institute as the author of the article identified in the ORE.

Funding: No funding was sought for this research.

Authors' contributions: The study design was conceived by JS and agreed by RMM and IL. The methodology was formulated by JS with advice from IL and RMM. JS performed the searching of the databases and removed duplicates. Title and abstract searching was completed by JS with RMM carrying out the $10 \%$ inter-reliability check. The full texts were screened independently by JS and RMM with agreement on the final selection. JS drafted the first version of the manuscript, and all authors contributed to, read and approved the final manuscript.

Acknowledgements: University of Exeter information specialist Morwenna Rogers for support with search strategies.

\section{References}

1. NHS England and NHS Digital. Hospital accident and emergency activity 2017-18. 2018. https://files.digital.nhs.uk/D3/CCB4FE/AE1718_\%20Annual\%20Summary.pdf Accessed 20/07/19.

2. NHS Improvement and NHS England. Allied health professions supporting patient flow: a quick guide. 2018. https://improvement.nhs.uk/documents/2485/AHPs_supporting_patient_flow_FINAL_.pdf Accessed 29/07/19.

3. Snaith B. Radiographer-led discharge in accident and emergency-the results of a pilot project. Radiography. 2007. Feb $1 ; 13(1): 13-7$.

4. Department of Health. The NHS plan: a plan for investment, a plan for reform. London: Stationery Office. 2000. (Cm; 4818-1). 
5. Brealey S, Scally A, Hahn S, Thomas N, Godfrey C, Coomarasamy A. Accuracy of radiographer plain radiograph reporting in clinical practice: a meta-analysis. Clinical radiology. 2005. Feb 1; 60(2):232-41.

6. Snaith B, Hardy M. The perceived impact of an emergency department immediate reporting service: An exploratory survey. Radiography. 2013. May 1;19(2):92-6

7. Woznitza N. Radiographer reporting. Journal of medical radiation sciences. 2014. Jun; 61(2):66-8.

8. Culpan G, Culpan A, Docherty P, Denton E. Radiographer reporting: A literature review to support cancer workforce planning in England. Radiography. 2019. Mar 14.

9. Howard M. Radiographer-led discharge: What are we waiting for? Imaging and Oncology. 2017. 34-38.

10. NHS England. Clinical Streaming in the Accident and Emergency (A\&E) Department. 2017. https://www.england.nhs.uk/wp-content/uploads/2017/07/principles-for-clinical-streaming-ae-department.pdf Accessed 20/07/19

11. Barter E. Radiographer-led discharge. Is this the next evolutionary step? Imaging and therapy practice. 2015. July $1: 5$.

12. Arksey H, O'Malley L. Scoping studies: towards a methodological framework. International journal of social research methodology. 2005. Feb 1; 8(1):19-32.

13. Knapp K, Ashton L, Rachuba S, Pitt, M. Demonstrator for advanced (radiographer) practice in emergency care (DARP). Report for Health Education South West Innovation Fund. 2016.

14. Tricco A, Lillie E, Zarin W, O'Brien K, Colquhoun H, Kastner M, Levac D, Ng C, Sharpe J, Wilson K, Kenny M. A scoping review on the conduct and reporting of scoping reviews. BMC medical research methodology. 2016. Dec; 16(1):15.

15. The Joanna Briggs Institute. Joanna Briggs Institute Reviewers' Manual: 2015 edition/supplement Adelaide: The Joanna Briggs Institute. 2015.

16. PROSPERO. International prospective register of systematic reviews. 2019. https://www.crd.york.ac.uk/prospero/ Accessed 30/05/2019.

17. Lancaster A, Hardy M. An investigation into the opportunities and barriers to participation in a radiographer comment scheme, in a multi-centre NHS trust. Radiography. 2012. May 1; 18(2):105-8.

18. Harris C, Hedges L, Valentine J. Handbook of research synthesis and meta-analysis. Russell Sage Foundation, New York. 2009.

19. Godin K, Stapleton J, Kirkpatrick SI, Hanning R, Leatherdale S. Applying systematic review search methods to the grey literature: a case study examining guidelines for school-based breakfast programs in Canada. Systematic reviews. 2015. Dec; 4(1):138.

20. Public Health England. Grey Literature: index and alternative sources and resources. 2019. https://phelibrary.kohaptfs.co.uk/greylit/\#greylit Accessed 01/08/2019.

21. Wohlin C. Guidelines for snowballing in systematic literature studies and a replication in software engineering. In Proceedings of the 18th international conference on evaluation and assessment in software engineering. 2014. May 13 (p. 38). ACM.

22. Martín-Martín A, Orduna-Malea E, Thelwall M, López-Cózar E. Google Scholar, Web of Science, and Scopus: A systematic comparison of citations in 252 subject categories. Journal of Informetrics. 2018 Nov 1; 12(4):1160-77.

23. Henderson D, Gray W, Booth L. Assessment of a reporting radiographer-led discharge system for minor injuries: a prospective audit over 2 years. Emerg Med J. 2013. Apr 1; 30(4):298-302.

24. Lumsden L, Cosson P. Attitudes of radiographers to radiographer-led discharge: A survey. Radiography. 2015. Feb 1; 21(1):61-7.

Page $17 / 20$ 
25. Howard M, Craib J. Radiographer led discharge in a minor injuries unit. Journal of Medical Imaging and Radiation Sciences. 2018. Sept Vol 49, Issue 3:S9. org/10.1016/j.jmir.2018.06.031

26. Rachuba S, Knapp K, Ashton L, Pitt M. Streamlining pathways for minor injuries in emergency departments through radiographer-led discharge. Operations research for health care. 2018. Dec 1; 19:44-56.

27. Jenkins L. Reporting Radiographer Led Discharge for Patients with Suspected Bony Injury in the Emergency Unit. 2015. nhswalesawards.wales.nhs.uk/opendoc/275756 Accessed 20/7/2019.

28. Øvretveit J, Leviton L, Parry G. Increasing the generalisability of improvement research with an improvement replication programme. BMJ quality \& safety. 2011. Apr 1; 20(Suppl 1):i87-91.

29. Kirkwood B, Sterne, J. Essential medical statistics. John Wiley \& sons. 2010.

30. Milner R, Snaith B. Are reporting radiographers fulfilling the role of advanced practitioner? Radiography. 2017. Feb $1 ; 23(1): 48-54$.

31. Damschroder L, Aron D, Keith R, Kirsh S, Alexander J, Lowery J. "Fostering implementation of health services research findings into practice: a consolidated framework for advancing implementation science." Implementation Science. 4(1): 50 .

32. Pinto A, Reginelli A, Pinto F, Lo Re G, Midiri F, Muzj C, Romano L, Brunese L. Errors in imaging patients in the emergency setting. The British journal of radiology. 2016. May; 89(1061):20150914.

33. Guly H. Diagnostic errors in an accident and emergency department. Emergency Medicine Journal. 2001. Jul 1; 18(4):263-9.

34. Hardy M, Hutton J, Snaith B. Is a radiographer led immediate reporting service for emergency department referrals a cost effective initiative? Radiography. 2013. Feb 1; 19(1):23-7.

35. Strudwick RM. An ethnographic study of the culture in a diagnostic imaging department (Doctoral dissertation, University of Salford). 2011.

36. Bajre M, Pennington M, Woznitza N, Beardmore C, Radhakrishnan M, Harris R, McCrone P. Expanding the role of radiographers in reporting suspected lung cancer: a cost-effectiveness analysis using a decision tree model. Radiography. 2017. Nov 1; 23(4):273-8.

37. Moore G, Audrey S, Barker M, Bond L, Bonell C, Hardeman W, Moore L, O'Cathain A, Tinati T, Wight D, Baird J. Process evaluation of complex interventions: Medical Research Council guidance. MRC Population Health Science Research Network, London. 2014.

38. Richards D, Hallberg I. Complex interventions in health: an overview of research methods. Routledge; 2015. Apr 17.

39. Munn Z, Pearson A, Jordan Z, Murphy F, Pilkington D. Action research in radiography: What it is and how it can be conducted. Journal of medical radiation sciences. 2013. Jun 1; 60(2):47-52.

40. Hendrich A, Chow M, Skierczynski B. Lu Z. A 36-hospital time and motion study: how do medical-surgical nurses spend their time? The Permanente Journal. 2008. 12(3):25.

\section{Figures}




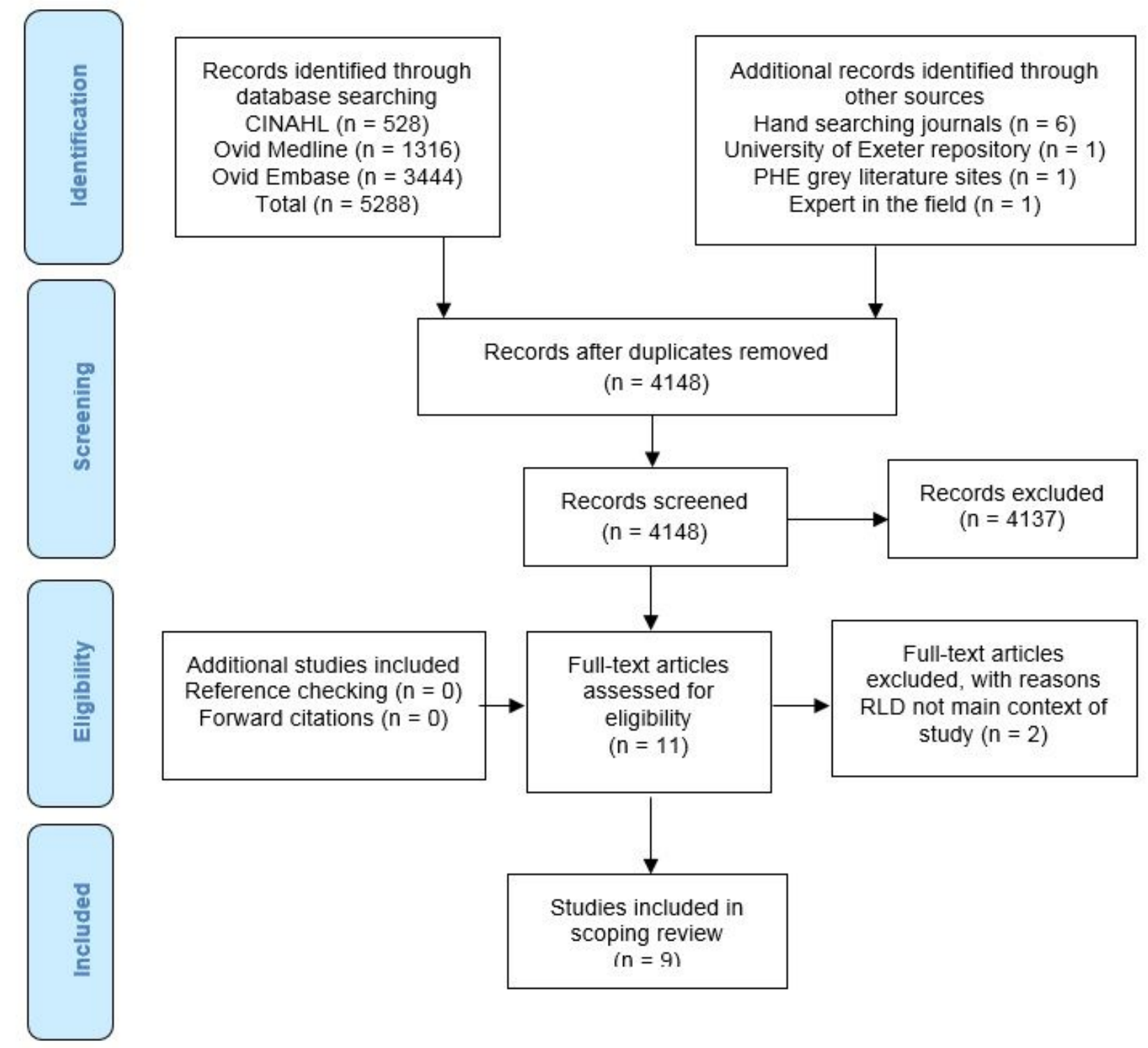

Figure 1

Flow of studies in the scoping review with reasons for exclusion 


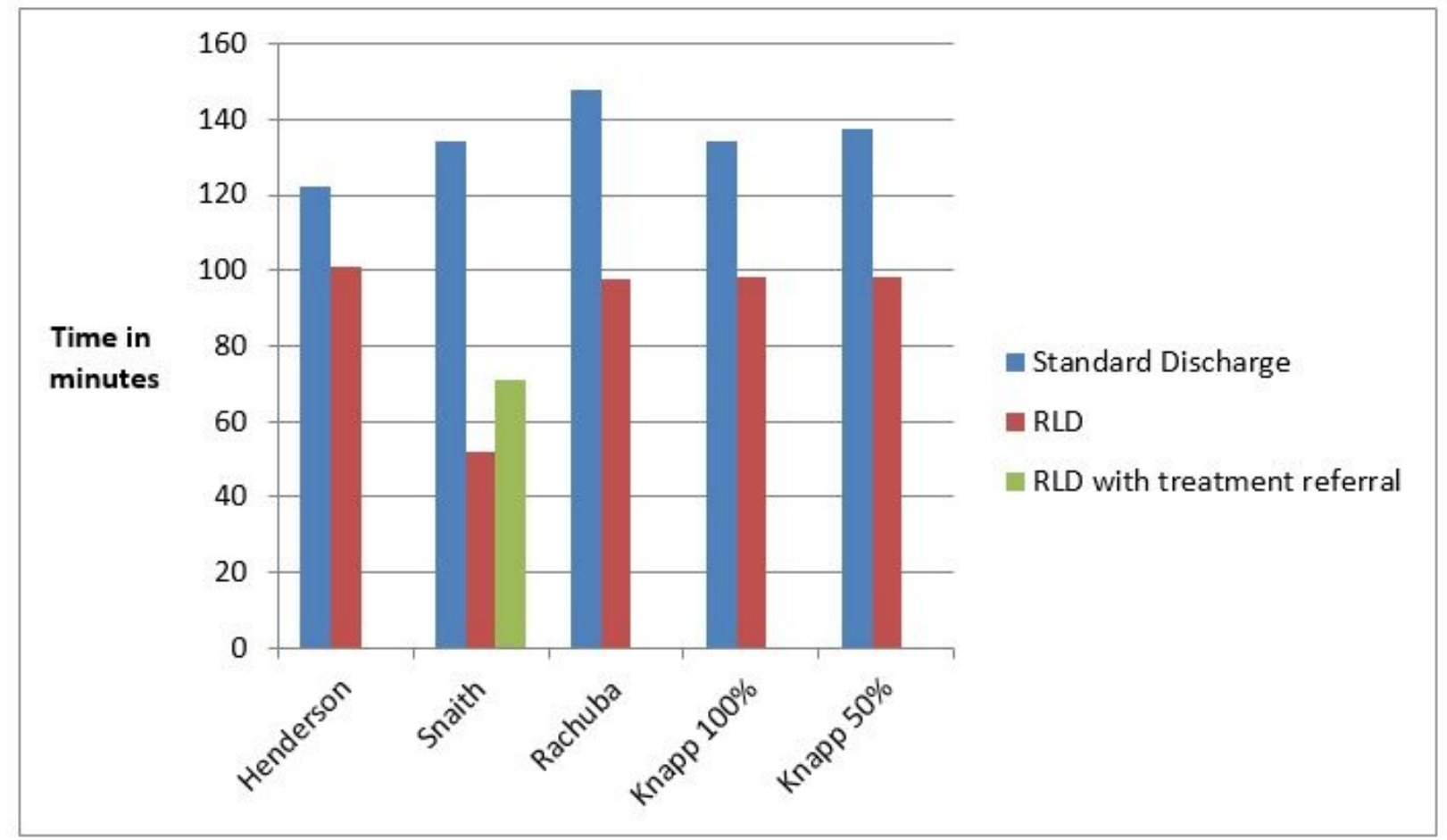

Figure 2

LOS in minutes for RLD compared to standard discharge. Knapp 50\% used to align with the other study methods. Knapp 100\% modelled continual RLD use. 